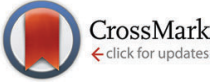

Cite this: Phys. Chem. Chem. Phys., $2016,18,25284$

Received 21st June 2016, Accepted 22nd August 2016

DOI: $10.1039 / c 6 c p 04279 a$

www.rsc.org/pccp

\title{
Rapid acquisition of wideline MAS solid-state NMR spectra with fast MAS, proton detection, and dipolar HMQC pulse sequences $\dagger$
}

\begin{abstract}
Aaron J. Rossini, ${ }^{a b}$ Michael P. Hanrahan ${ }^{a b}$ and Martin Thuo ${ }^{b c}$
The solid-state NMR spectra of many NMR active elements are often extremely broad due to the presence of chemical shift anisotropy (CSA) and/or the quadrupolar interaction (for nuclei with spin $I>1 / 2$ ). These NMR interactions often give rise to wideline solid-state NMR spectra which can span hundreds of $\mathrm{kHz}$ or several $\mathrm{MHz}$. Here we demonstrate that by using fast MAS, proton detection and dipolar hetero-nuclear multiple-quantum (D-HMQC) pulse sequences, it is possible to rapidly acquire 2D spectra which correlate ${ }^{1} \mathrm{H}$ chemical shifts to the indirectly detected wideline MAS powder patterns of dipolar coupled heteronuclei. The D-HMQC pulse sequence enables broadband excitation of the wideline hetero-nuclear NMR spectrum and provides higher sensitivity by detecting the narrower and more sensitive ${ }^{1} \mathrm{H}$ NMR signal. This approach is demonstrated for the rapid acquisition of $2 \mathrm{D}{ }^{1} \mathrm{H}$ detected ${ }^{195} \mathrm{Pt}$ solid-state NMR spectra of cisplatin and transplatin and the ${ }^{71} \mathrm{Ga}$ solid-state NMR spectrum of a self-assembled Ga coordination polymer of unconfirmed structure. This approach should be broadly applicable for the rapid acquisition of wideline MAS solid-state NMR spectra of moderately abundant NMR nuclei.
\end{abstract}

\section{Introduction}

Solid-state nuclear magnetic resonance (NMR) spectroscopy is an extremely powerful probe of structure and dynamics for both crystalline and partially ordered/amorphous solid materials. ${ }^{1-7}$ Many of the elements of the periodic table possess NMR active nuclei that can potentially be studied by solid-state NMR spectroscopy. The solid-state NMR spectra of heavier spin-1/2 nuclei (e.g., ${ }^{77} \mathrm{Se},{ }^{113} \mathrm{Cd},{ }^{109} \mathrm{Ag},{ }^{183} \mathrm{~W},{ }^{195} \mathrm{Pt},{ }^{207} \mathrm{~Pb}$, etc.) are frequently significantly broadened by chemical shift anisotropy (CSA). ${ }^{6,8}$ With the increasing availability of high field NMR spectrometers the effects of CSA are becoming more important even for lighter spin $1 / 2$ nuclei such as ${ }^{13} \mathrm{C},{ }^{15} \mathrm{~N},{ }^{19} \mathrm{~F}$ and ${ }^{31} \mathrm{P}$ since the broadening due to CSA scales with the strength of the applied field. Similarly, many integer and half-integer quadrupolar nuclei give rise to very broad solid-state NMR spectra due to inhomogeneous broadening by the quadrupolar interaction. ${ }^{8-12}$ Here we refer to a solidstate NMR spectrum covering a frequency range greater than $200 \mathrm{kHz}$ as a wideline spectrum. Wideline solid-state NMR spectra

\footnotetext{
${ }^{a}$ Iowa State University, Department of Chemistry, Ames, IA, 50011, USA.

E-mail: arossini@iastate.edu; Tel: +1-515-294-8952

${ }^{b}$ US DOE Ames Laboratory, Ames, Iowa, 50011, USA

${ }^{c}$ Iowa State University, Materials Science and Engineering Department, Ames, IA, 50011, USA

$\dagger$ Electronic supplementary information (ESI) available: Additional solid-state NMR spectra and numerical simulations of solid-state NMR experiments is available. See DOI: $10.1039 / \mathrm{c} 6 \mathrm{cp} 04279 \mathrm{a}$
}

of spin-1/2 and quadrupolar nuclei have been used to obtain valuable information about structure, bonding and dynamics for a variety of organic, inorganic and biological systems. ${ }^{13-33}$

Unfortunately, the broadening of solid-state NMR spectra often results in a drastic loss in sensitivity. This is because the sensitivity of an NMR experiment is inversely proportional to the square root of the observed linewidth of the signal when a standard Bloch decay or spin echo pulse sequence is used for acquisition [sensitivity $\left.\propto(\mathrm{FWHH})^{-1 / 2}=\left(\pi T_{2}{ }^{*}\right)^{1 / 2}\right]$. For this reason special wideline solid-state NMR techniques based upon the Carr-Purcell-Meiboom-Gill (CPMG) pulse sequence are typically used to reduce experiment times on static samples. ${ }^{8,34-36}$ CPMG experiments exploit the fact that in solids with inhomogeneously broadened NMR spectra, the effective refocused transverse relaxation time $\left(T_{2}{ }^{\prime}\right.$, measured with a spin echo or CPMG experiment) is usually much longer than the apparent transverse relaxation time $\left(T_{2}{ }^{*}\right)$ determined by the observed linewidth. With CPMG detection, multiple spin echoes are acquired in each scan and sensitivity is proportional to the square root of $T_{2}{ }^{\prime}$, rather than the typically much shorter $T_{2}{ }^{*}$. CPMG pulse sequences can provide a dramatic increase in sensitivity. ${ }^{8,34-36}$

Wideline solid-state NMR spectra are also challenging to acquire due to their broad frequency ranges and the limited excitation bandwidths of conventional pulses. This can be addressed by incorporating frequency swept WURST pulses into static CPMG experiments to improve the bandwidth of excitation and refocusing pulses (WCPMG) ${ }^{37,38}$ and/or cross-polarization 
steps (BRAIN-CP). ${ }^{8,39}$ In many cases the excitation/refocusing bandwidth is insufficient, even with frequency swept pulses, and a frequency stepped, piece-wise acquisition of the wideline NMR spectrum must be performed (i.e., using the VOCS procedure). ${ }^{8,14,16}$ Static CPMG experiments incorporating frequency swept pulses often provide the best absolute sensitivity since large sample volumes can be used and large excitation bandwidths can be realized. However, the analysis of a solid-state NMR spectrum of a stationary powdered sample will be challenging if there are overlapping powder patterns arising from multiple sites, therefore, MAS experiments could be preferable since they can provide higher resolution.

Application of MAS to ordered/crystalline systems results in narrowing of the peaks and substantially improves the resolution of solid-state NMR spectra of spin-1/2 nuclei. However, in disordered materials or nuclei with other broadening mechanisms the peaks may only be partially narrowed under MAS and often remain broad due to combinations of chemical shift distributions from disorder, susceptibility broadening, second-order quadrupolar interactions, paramagnetic interactions, scalar/dipolar coupling to quadrupolar nuclei, temperature gradients due to MAS, etc. When the peaks are inhomogeneously broadened under MAS, rotorsynchronized CPMG experiments can be applied to improve sensitivity. ${ }^{35,40-42}$ However, MAS solid-state NMR spectra of heavy spin-1/2 nuclei such as ${ }^{195} \mathrm{Pt}$ and ${ }^{207} \mathrm{~Pb}$ often possess isotropic and spinning sideband peaks that are several hundred $\mathrm{Hz}$ or several $\mathrm{kHz}$ broad, even in highly crystalline materials. ${ }^{15,24,43-49}$ This is an unfavorable regime where $T_{2}{ }^{*} \approx T_{2}{ }^{\prime}$ and CPMG techniques will provide negligible gains in sensitivity.

An additional complication of MAS experiments arises when the CSA is large. The MAS sideband manifold may cover hundreds of $\mathrm{kHz}$ and the signal will be dispersed into numerous sidebands, making it difficult to uniformly excite or refocus the spectrum. For example, square planar Pt complexes usually give rise to wideline ${ }^{195} \mathrm{Pt}$ solid-state NMR spectra covering $>800 \mathrm{kHz}$ since the span $(\Omega)$ is often greater than $7000 \mathrm{ppm}^{27,43}$ Conventional ramped CPMAS experiments are typically not applicable in such cases since they suffer from very poor bandwidth due to the narrowband spin lock pulse in the CP step. ${ }^{50}$ Subsequently, direct excitation experiments, possibly incorporating frequency swept shaped pulses, are often used to acquire wideline MAS NMR spectra. ${ }^{51-53}$ Similar to static wideline NMR experiments, if the MAS sideband manifold is not uniformly excited, frequency stepped acquisition of the MAS pattern may be performed. ${ }^{49,51,54}$ However, in diamagnetic materials direct excitation experiments often give poor sensitivity due to the long longitudinal relaxation times of the heavy spin-1/2 nuclei in solids. ${ }^{27,43,51}$ We note that broadband polarization transfer from wideline MAS ${ }^{1} \mathrm{H}$ NMR signals has been demonstrated with dipolar TEDOR and INEPT pulse sequences in paramagnetic materials, but, they have not been demonstrated on diamagnetic materials. ${ }^{52,53,55,56}$

Here we demonstrate that many of the challenges associated with the acquisition of MAS wideline solid-state NMR spectra can be alleviated by fast MAS ${ }^{1} \mathrm{H}$-detected dipolar hetero-nuclear multiple quantum coherence (D-HMQC) 2D correlation experiments. The dipolar-HMQC pulse sequence is depicted in Fig. 1A
(A)
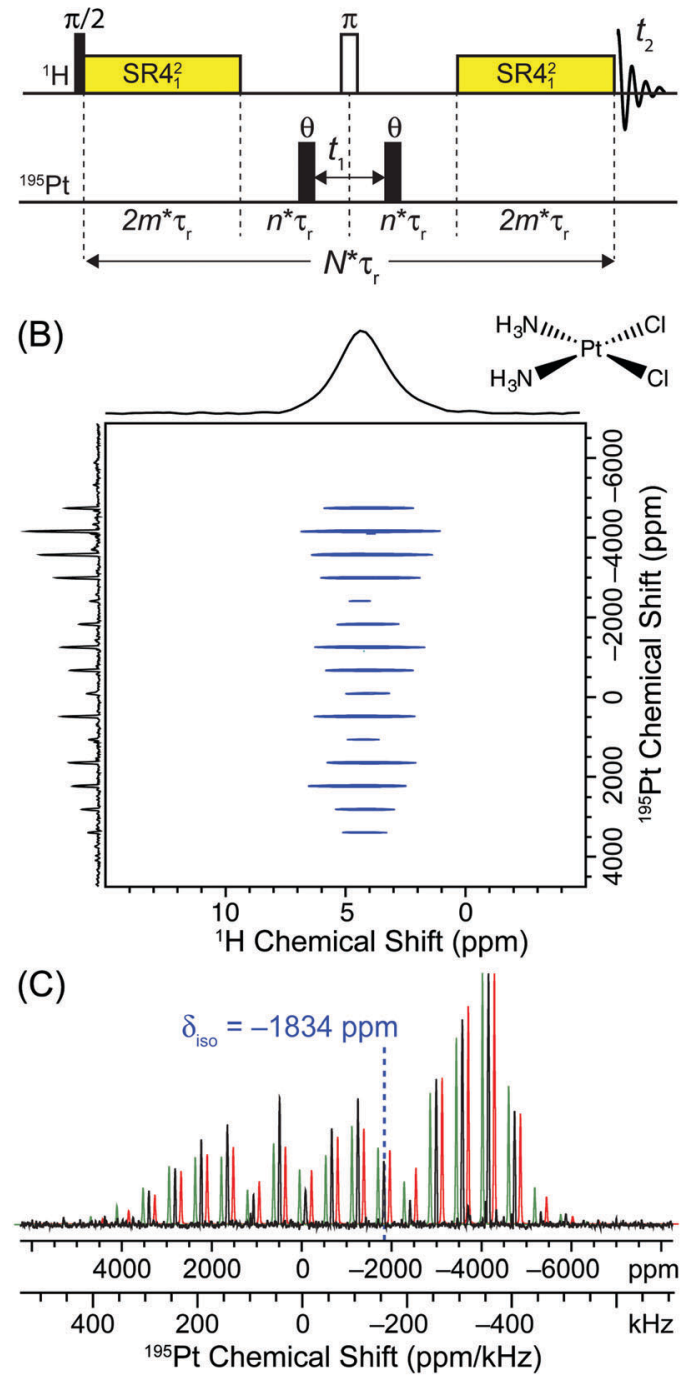

Fig. 1 (A) Constant time D-HMQC pulse sequence used to acquire 2D ${ }^{1} \mathrm{H}$-detected dipolar correlation spectra. The spin echo block in the middle of the sequence is fixed to a constant duration $\left(2 n \times \tau_{r}>t_{1, \max }\right)$ and the $\theta$ pulses are stepped outwards to enable arbitrary, rotor asynchronous $t_{1}$ increments. (B) The $2 \mathrm{D}{ }^{1} \mathrm{H}-{ }^{195} \mathrm{Pt} \mathrm{D}-\mathrm{HMQC}$ correlation spectrum of cisplatin (Alfa Aesar) acquired with a $50 \mathrm{kHz}$ MAS frequency, 32 scans per increment, a $0.5 \mathrm{~s}$ recycle delay, $m=27\left(2 m \times \tau_{\mathrm{r}}=1.08 \mathrm{~ms}\right), n=6\left(n \times \tau_{\mathrm{r}}=120 \mu \mathrm{s}\right), 512$ individual $t_{1}$ increments (256 hyper-complex points) and $t_{1}$ was incremented in steps of $0.8 \mu \mathrm{s}$ (1.25 MHz indirect dimension spectral width). $\theta$ pulses $0.6 \mu \mathrm{s}$ in duration with a $278 \mathrm{kHz}$ rf field (60 tip angle) were used. The total experiment time was 2.3 hours. (C) The positive projection of the indirectly detected ${ }^{195} \mathrm{Pt}$ dimension (black trace) is compared to an analytical simulation with the previously reported values of $\Omega$ and $\kappa$ (green trace $\left.\delta_{\text {iso }}=-1834 \mathrm{ppm} ; \Omega=8975 \mathrm{ppm}, \kappa=-0.96\right) .{ }^{51}$ An analytical fit of the sideband manifold yielded similar CS tensor parameters (red trace, $\delta_{\text {iso }}=$ -1834 ppm; $\Omega=8561$ ppm, $\kappa=-0.96)$. The simulated sideband manifolds were offset from the experimental one to allow better comparison of sideband intensities.

and is based upon the classic solution NMR pulse sequence. Gan and Bodenhausen separately demonstrated the use of HMQC pulse sequences in the solid state for the indirect detection of isotropic ${ }^{14} \mathrm{~N}$ solid-state NMR spectra by ${ }^{13} \mathrm{C} .{ }^{57-59}$ Further development and refinement of D-HMQC pulse sequences included 
optimization of dipolar recoupling schemes and addition of homo-nuclear decoupling during the indirect dimension evolution time $\left(t_{1}\right) .^{60-65}$ The advantages of this pulse sequence for obtaining dipolar correlation NMR spectra with half-integer and integer quadrupolar spins are clear; ${ }^{60-66}$ the only manipulation of the hetero-nucleus involves two relatively broadband $\pi / 2$ pulses for excitation and reconversion. Importantly, the D-HMQC pulse sequence also incorporates efficient proton detection, which can provide a large gain in sensitivity. ${ }^{67-70}$

The D-HMQC pulse sequence is applied here for the rapid indirect detection of MAS wideline solid-state NMR spectra of ${ }^{195} \mathrm{Pt}(I=1 / 2)$ and the quadrupolar ${ }^{71} \mathrm{Ga}(I=3 / 2)$ isotopes. It was very recently suggested that D-HMQC could be beneficial for obtaining solid-state NMR spectra of spin-1/2 nuclei with large CSA such as ${ }^{195} \mathrm{Pt}^{71}$ However, to the best of our knowledge, the D-HMQC pulse sequence has never been demonstrated for indirect detection of a wideline MAS solid-state NMR spectrum. This is because in 2D D-HMQC spectra the spectral width of the indirect dimension is normally set equal to the MAS frequency or half of the MAS frequency (i.e., by using a $t_{1}$-increment of one or two rotor periods, respectively). Here we show that it is possible to use an arbitrary indirect spectral width in the D-HMQC pulse sequence and rapidly indirectly detect wideline MAS solid-state NMR spectra. The high rf powers delivered by the small diameter rf coil of a fast MAS probe provide large excitation bandwidths, enabling the uniform excitation of the indirectly detected wideline solid-state NMR spectra.

\section{Results and discussion}

\section{MAS wideline ${ }^{1} \mathrm{H}-{ }^{195} \mathrm{Pt}$ D-HMQC experiments}

The square planar platinum complexes cisplatin $\left(\right.$ cis- $\left.\left(\mathrm{NH}_{3}\right)_{2} \mathrm{PtCl}_{2}\right)$ and transplatin (trans- $\left.\left(\mathrm{NH}_{3}\right)_{2} \mathrm{PtCl}_{2}\right)$ were chosen as a test case since these complexes possess some of largest known CSA $(\Omega>$ $8000 \mathrm{ppm}$ in both cases). ${ }^{43}$ The large CSA gives rise to ${ }^{195} \mathrm{Pt}$ solid-state NMR spectra which cover $>800 \mathrm{kHz}$ at the moderate magnetic field strength of $9.4 \mathrm{~T}$ used here $\left(\nu_{0}\left({ }^{1} \mathrm{H}\right)=400 \mathrm{MHz}\right.$, $\left.\nu_{0}\left({ }^{195} \mathrm{Pt}\right)=86 \mathrm{MHz}\right) .{ }^{43}{ }^{195} \mathrm{Pt}$ is a spin- $1 / 2$ nucleus which possesses good NMR receptivity [natural abundance $=33.8 \%$ and $R\left({ }^{195} \mathrm{Pt}\right) /$ $\left.R\left({ }^{13} \mathrm{C}\right)=20.7\right] \cdot{ }^{72}$ However, ${ }^{195} \mathrm{Pt}$ solid-state NMR is often challenging due to the tendency of ${ }^{195} \mathrm{Pt}$ to give rise to very broad solid-state NMR spectra because of large CSA.

Fig. 1B shows the $2 \mathrm{D}^{1} \mathrm{H}-{ }^{195} \mathrm{Pt}$ D-HMQC spectrum of cisplatin acquired at $9.4 \mathrm{~T}$ with a $1.3 \mathrm{~mm}$ diameter rotor and an MAS frequency of $50 \mathrm{kHz}$. The $\mathrm{SR} 4_{1}^{2}$ symmetry based dipolar recoupling sequence ${ }^{73}$ was used in the D-HMQC pulse sequence here since it is insensitive to rf field inhomogeneity and offsets and subsequently yields better efficiency than rotary resonance recoupling $\left(\mathrm{R}^{3}\right) .{ }^{61}$ A second ${ }^{1} \mathrm{H}-{ }^{195} \mathrm{Pt}$ D-HMQC spectrum of cisplatin was also acquired with an MAS frequency of $40 \mathrm{kHz}$ to confirm the position of the isotropic chemical shift (Fig. S1, ESI $\dagger$ ). The $1.3 \mathrm{~mm}$ diameter rotor enables fast MAS which provides reasonable ${ }^{1} \mathrm{H}$ NMR resolution and improved sensitivity by lengthening the ${ }^{1} \mathrm{H} T_{2}{ }^{\prime}$ and narrowing the ${ }^{1} \mathrm{H}$ NMR lines. As expected, the $2 \mathrm{D}$ $\mathrm{D}-\mathrm{HMQC}$ spectrum of cisplatin correlates the amine protons with a ${ }^{1} \mathrm{H}$ chemical shift of $4.3 \mathrm{ppm}$ to the wideline MAS ${ }^{195} \mathrm{Pt}$ NMR sideband manifold. This 2D spectrum was acquired in an experiment time of only 2.3 hours! This is despite the fact that cisplatin was found to possess an unfavorable $11.7 \mathrm{~s}{ }^{1} \mathrm{H}$ longitudinal relaxation time $\left(T_{1}\right)$. The $2 \mathrm{D}^{1} \mathrm{H}^{-}{ }^{195} \mathrm{Pt} \mathrm{D}-\mathrm{HMQC}$ experiment time is much shorter than those reported by Lucier et al. for acquisition of static ${ }^{195} \mathrm{Pt}$ solid-state NMR spectra of cisplatin with direct excitation WCPMG experiments. ${ }^{43}$ Their frequency-stepped, piece-wise acquisition of the static ${ }^{195} \mathrm{Pt}$ NMR spectrum required acquisition of 11-subspectra and 9 hours total experiment time (using large sample volumes with $5 \mathrm{~mm}$ glass tubes). ${ }^{43}$ Here, the entire MAS sideband manifold could be uniformly excited with a single transmitter offset. This provides considerable time savings and simplifies acquisition. See below for a comparison of direct and indirectly detected ${ }^{195} \mathrm{Pt}$ solid-state NMR spectra.

There are several clear advantages of the fast MAS D-HMQC approach for acquisition of MAS wideline NMR spectra: (i) the pulse sequence enables broadband excitation, which is sufficient to acquire the wideline MAS ${ }^{195} \mathrm{Pt}$ solid-state NMR spectrum of cisplatin, (ii) a high resolution MAS solid-state NMR spectrum is obtained permitting accurate measurement of the isotropic chemical shift, CS tensor parameters and possibly enabling overlapping powder patterns to be resolved either in the indirectly detected high resolution ${ }^{195} \mathrm{Pt}$ dimension or by correlations to different ${ }^{1} \mathrm{H}$ chemical shifts, (iii) ${ }^{1} \mathrm{H}$ detection provides a substantial absolute gain in signal to noise ratio and significantly reduces experiment times, (iv) the small diameter rotors required for fast MAS solid-state NMR typically only require $c a .5$ to $10 \mu \mathrm{L}$ of sample.

\section{Constant time D-HMQC}

In order to indirectly detect the wideline MAS ${ }^{195} \mathrm{Pt}$ sideband manifold a D-HMQC pulse sequence with a constant echo time was used (i.e., constant $n$, Fig. 1A). In the previous implementations of HMQC in solid-state NMR the indirect dimension evolution period $\left(t_{1}\right)$ was incremented in a rotor-synchronized manner and the indirect spectral width was set to the MAS frequency. ${ }^{57,60,63,64}$ This was accomplished by simultaneously incrementing the separation of the $\theta$ pulses by one rotor cycle and increasing the duration of the central spin echo block (by simultaneously incrementing $n$ and $t_{1}$, Fig. 1A). ${ }^{57,60,63,64}$ Setting the $t_{1}$-increment to the rotor period $\left(\tau_{\mathrm{r}}\right)$ eliminates sidebands in the indirect dimension and provides maximum sensitivity since the indirect dimension signal will always sample the top of the rotary echoes. Here a constant echo time version of D-HMQC was used because the $t_{1}$-increment and the spectral width of the indirect dimension can easily be set to any value. This is realized by fixing $n$ to a constant value for all $t_{1}$-increments within the $2 \mathrm{D}$ data set, and then incrementing the $\theta$ pulses outwards from the central $\pi$-pulse. Note that the constant time pulse sequence also has the advantage that broadening in the indirect dimension due to ${ }^{1} \mathrm{H} T_{2}{ }^{\prime}$ relaxation is eliminated.

However, there are several minor disadvantages arising from the use of a rotor asynchronous $t_{1}$-increment: (i) the total duration of the central spin echo block must be set so that it is greater than the maximum $t_{1}$ evolution time $\left(2 n \times \tau_{\mathrm{r}}>t_{1, \max }\right)$. 
Therefore, depending upon the $T_{2}{ }^{\prime}$ of the ${ }^{1} \mathrm{H}$ nuclei a reduction in signal to noise ratio will occur because there is transverse relaxation during the long spin echo element used for all of the increments in the $2 \mathrm{D}$ experiment. Note that it is possible to incorporate decoupling schemes into the spin echo block to extend ${ }^{1} \mathrm{H}_{2}{ }^{\prime}$ and partially address this issue. ${ }^{63,64}$ (ii) When the indirect dimension spectral width is very large (i.e., the $t_{1}$-increment is very small), then a larger number of points in the indirect dimension are required to capture the decay of the indirectly detected signal. However, in practice truncation of the indirect dimension will broaden the peaks and does not substantially affect the relative intensities of the sidebands. (iii) When the $t_{1}$-increment is rotor asynchronous, many of the increments composing the 2D spectrum contain very little signal. This is because when the CSA is large signal is only observed when the $t_{1}$ evolution period approaches integer multiples of the rotor cycle (Fig. S2, ESI $\dagger$ ). A larger indirect dimension spectral width therefore decreases the signal to noise ratio and increases the experiment time compared to rotor synchronized indirect dimension spectral widths. Despite these drawbacks, constant time D-HMQC experiments with large indirect dimension spectral widths enables the rapid indirect detection of MAS wideline NMR spectra as evidenced by the short experiment times required for ${ }^{1} \mathrm{H}-{ }^{195} \mathrm{Pt} \mathrm{D}-\mathrm{HMQC}$ experiments on cisplatin and transplatin ( $\mathrm{ca}$. 2 hours each). Below we directly quantify the sensitivity gains provided by indirect detection ${ }^{1} \mathrm{H}-{ }^{195} \mathrm{Pt} \mathrm{D}-\mathrm{HMQC}$ as compared to direct detection ${ }^{195} \mathrm{Pt}$ NMR experiments.

\section{Quantifying the sensitivity gains provided by indirect detection}

The rapid acquisition of the wideline MAS ${ }^{195} \mathrm{Pt}$ solid-state NMR spectra is enabled by the large gain in sensitivity provided by ${ }^{1} \mathrm{H}$ detection. Here we quantitatively compare the sensitivity of the indirectly detected MAS ${ }^{1} \mathrm{H}-{ }^{195} \mathrm{Pt}$ D-HMQC spectrum of cisplatin to (i) a direct excitation MAS ${ }^{195} \mathrm{Pt}$ Bloch decay (pulse-acquire) NMR spectrum, (ii) a ${ }^{1} \mathrm{H}^{-195} \mathrm{Pt}$ RESPIRATION-CPMAS ${ }^{74}$ spectrum and (iii) a direct excitation ${ }^{195} \mathrm{Pt}$ WCPMG static solid-state NMR spectrum. By measuring the factors that restrict the efficiency of the HMQC experiments it is possible to obtain a better understanding of detection limits and identify the factors that control efficiency.

The gain in sensitivity $(\xi)$ provided by indirect ${ }^{1} \mathrm{H}$ detection as compared to direct excitation and detection of ${ }^{195} \mathrm{Pt}$ can be estimated by the following modified expression: ${ }^{67,75}$

$$
\begin{aligned}
\xi= & f_{\mathrm{HMQC}}{ }^{2}\left(\frac{\gamma_{1} \mathrm{H}}{\gamma_{195} \mathrm{Pt}}\right)^{5 / 2}\left(\frac{W^{195} \mathrm{Pt}}{W_{{ }^{1} \mathrm{H}}}\right)^{\frac{1}{2}}\left(\frac{1}{\alpha}\right)^{\frac{1}{2}}\left(\frac{T_{1}\left({ }^{195} \mathrm{Pt}\right)}{T_{1}\left({ }^{1} \mathrm{H}\right)}\right)^{\frac{1}{2}} \\
& \times\left(\frac{Q^{1} \mathrm{H}}{Q^{195} \mathrm{Pt}}\right)\left(\frac{A_{1} \mathrm{H}}{A_{195} \mathrm{Pt}}\right)\left(\frac{\Omega}{\nu_{\mathrm{rot}}}\right), \text { for } \Omega>\nu_{\mathrm{rot}}
\end{aligned}
$$

here $\gamma_{1 \mathrm{H}}$ and $\gamma_{195 \mathrm{Pt}}$ are the gyromagnetic ratios, $f_{\mathrm{HMQC}}$ is the efficiency of the polarization transfer in the ${ }^{1} \mathrm{H}-{ }^{195} \mathrm{Pt}$ HMQC experiment, $T_{1}$ are the longitudinal relaxation times of ${ }^{195} \mathrm{Pt}$ and ${ }^{1} \mathrm{H}, W_{j}$ are the observed linewidths, $Q_{j}$ are the quality factors $(Q)$ of the ${ }^{1} \mathrm{H}$ and ${ }^{195} \mathrm{Pt}$ channels of the probe, $A_{j}$ are determined by other factors depending upon the electrical components of the probe and transmission/reception of the signals. ${ }^{67,75} \alpha$ is a factor related to the dimensionality of the measurement and the signal decay in the $t_{1}$ dimension. $\alpha=1$ for a comparison of $1 \mathrm{D}^{1} \mathrm{H}$ detected and $1 \mathrm{D}$ directly detected spectra. ${ }^{67}$ We have directly measured for the $2 \mathrm{D}$ experiment that $\alpha^{1 / 2}$ is between 4 and 15 (vide infra). The final term $\left(\Omega / \nu_{\text {rot }}\right)$ accounts for the fact ${ }^{1} \mathrm{H}$ indirect detection provides an additional gain in sensitivity because all of the spinning sidebands are "folded" under the narrow isotropic ${ }^{1} \mathrm{H}$ NMR signal when indirectly detecting the MAS ${ }^{195} \mathrm{Pt}$ NMR signal. For cisplatin at $9.4 \mathrm{~T}, \Omega \approx 9000 \mathrm{ppm}=775 \mathrm{kHz}$ and with a $50 \mathrm{kHz}$ MAS rate this translates into an additional factor of $c a .15$ gain in sensitivity for indirect $v s$. direct detection. However, for acquisition of the $2 \mathrm{D}$ spectrum the term $\left(\Omega / \nu_{\text {rot }}\right)$ in eqn (1) will likely be cancelled by the increase in $\alpha$ because signal is only observed at or near the rotary echoes (Fig. S2, ESI $\dagger$ ). The factors $W_{\mathrm{H}}, \alpha$ and $f$ should all become more favorable at faster spinning frequencies, therefore, faster MAS frequencies should provide both the highest gain in sensitivity and the best absolute sensitivity.

The gain in sensitivity provided by indirect detection can be illustrated and partly quantified by examining the SNR of various ${ }^{1} \mathrm{H}$ solid-state NMR spectra of cisplatin. Fig. 2 compares a $50 \mathrm{kHz}$ MAS ${ }^{1} \mathrm{H}$ solid-state NMR spectra of cisplatin acquired with a standard rotor synchronized spin echo pulse sequence (Fig. 2A), a spin echo pulse sequence with $\mathrm{SR} 4{ }_{1}^{2}$ recoupling applied for a total duration of $2.16 \mathrm{~ms}$ (Fig. 2B) and a ${ }^{1} \mathrm{H}-{ }^{195} \mathrm{Pt}$ D-HMQC spectrum acquired with the empirically optimized $2.16 \mathrm{~ms}$ total $\mathrm{SR} 4{ }_{1}^{2}$ recoupling (Fig. 2C). All spectra were acquired with 16 scans and a $14.8 \mathrm{~s}$ recycle delay (which corresponds to $1.3 \times T_{1}\left({ }^{1} \mathrm{H}\right)$ ) and processed with $200 \mathrm{~Hz}$ exponential line broadening. The ${ }^{1} \mathrm{H}$ spin echo NMR spectrum has a SNR of $c a .14600$. The ${ }^{1} \mathrm{H}$ spin echo spectrum acquired with $\mathrm{SR} 4{ }_{1}^{2}$ recoupling applied for $2.16 \mathrm{~ms}$ has a signal which is reduced by a factor of $c a .6(0.09 / 0.015)$. This is due to relaxation during the $2.16 \mathrm{~ms}$ recoupling period, however, the recoupled spin echo spectrum still has a signal to noise ratio of ca. 2100. In the ${ }^{1} \mathrm{H}_{-}{ }^{195} \mathrm{Pt}$ D-HMQC spectrum the ${ }^{1} \mathrm{H}$ NMR signal is reduced by a factor 0.015 and 0.09 compared to the spin echo and the recoupled spin echo, respectively. However, despite the low efficiency and losses due to relaxation the ${ }^{1} \mathrm{H}-{ }^{195} \mathrm{Pt}$ D-HMQC spectrum still has a SNR of $c a .166$ in only 16 scans, corresponding to a sensitivity $\left[\mathrm{SNR} /(\text { time })^{-1 / 2}\right]$ of $84 \mathrm{~min}^{-1 / 2}$.

Comparison of the signal intensities in Fig. 2 suggests $f_{\mathrm{HMQC}}{ }^{2} \approx 0.015$ and $f_{\mathrm{HMQC}} \approx 0.12$. However, taking into account that ${ }^{195} \mathrm{Pt}$ is only $33.8 \%$ abundant, this suggests $f_{\mathrm{HMQC}} \approx$ 0.36 and $f_{\mathrm{HMQC}}{ }^{2} \approx 0.13$. Using eqn (1) with $\left(\gamma_{1_{\mathrm{H}}} / \gamma_{195 \mathrm{Pt}}\right)^{5 / 2}=47$, $\left(\Omega / \nu_{\text {rot }}\right)=15, f_{\mathrm{HMQC}}{ }^{2} \approx 0.13,\left(W_{195 \mathrm{Pt}} / W_{{ }_{1 \mathrm{H}}}\right)=1.2$ and assuming $\left[T_{1}\left({ }^{195} \mathrm{Pt}\right) / T_{1}\left({ }^{1} \mathrm{H}\right)\right]^{1 / 2} \approx 3$ and that all other factors/ratios in eqn (1) equal 1 , we calculate $\xi=330$. This is for comparison of the sensitivity of the first increment of a ${ }^{1} \mathrm{H}-{ }^{195} \mathrm{Pt}$ D-HMQC experiment and a ${ }^{195} \mathrm{Pt}$ NMR spectrum obtained with direct excitation and detection.

In order to estimate the sensitivity gain for a $2 \mathrm{D}{ }^{1} \mathrm{H}-{ }^{195} \mathrm{Pt}$ D-HMQC experiment, $\alpha^{1 / 2}$ was calculated by comparing the SNR of the first increment of the 2D D-HMQC spectrum to the SNR of the indirect dimension of the $2 \mathrm{D}$ spectrum. The SNR of the first increment is 15 (with 32 scans $\times 0.5 \mathrm{~s}$ ), and this corresponds to a sensitivity of $29 \mathrm{~min}^{-1 / 2}$. In the $2 \mathrm{D}$ spectrum the SNR of the most intense peak in the ${ }^{195} \mathrm{Pt}$ dimension is 22 
(A)
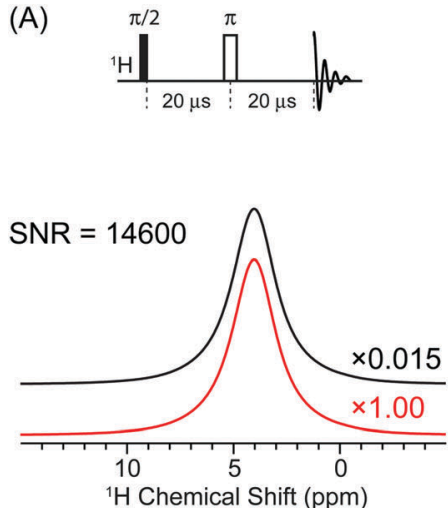

(B)
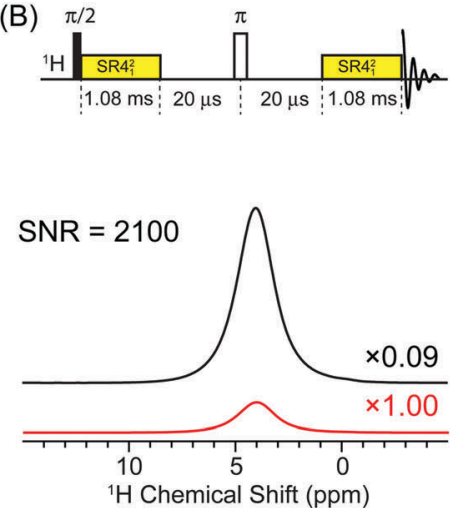

(C)
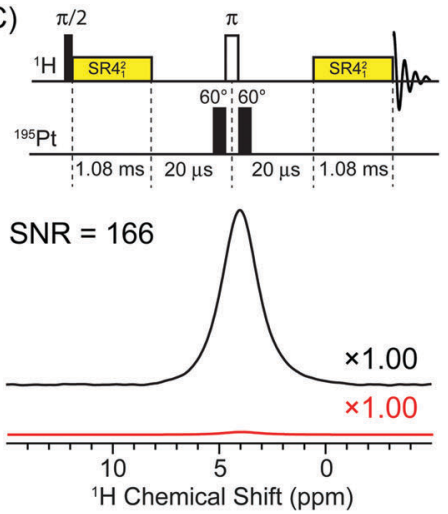

Fig. 2 Comparison of $50 \mathrm{kHz}$ MAS ${ }^{1} \mathrm{H}$ solid-state NMR spectra of cisplatin acquired with (A) a rotor synchronized spin-echo pulse sequence, (B) a rotor synchronized spin echo with $2.16 \mathrm{~ms}$ of SR4 ${ }_{1}^{2}$ recoupling and $(C)$ a $1 D^{1}{ }^{1}-{ }^{195} \mathrm{Pt} \mathrm{D}-\mathrm{HMQC}$ experiment with $2.16 \mathrm{~ms}$ of SR4 ${ }_{1}^{2}$ recoupling. All spectra were acquired with 16 scans and a $14.8 \mathrm{~s}$ recycle delay which corresponds to $1.3 \times T_{1}$. The upper black traces shows all ${ }^{1} \mathrm{H}$ NMR spectra scaled to the same height, with the scaling factors relative to ${ }^{1} \mathrm{H}-{ }^{195} \mathrm{Pt} \mathrm{D}-\mathrm{HMQC}$ spectrum indicated to the right of each spectrum. The lower red traces show the ${ }^{1} \mathrm{H}$ NMR spectra plotted on the same absolute scale. The signal to noise is indicated to the left of each spectrum.

(with 32 scans $\times 0.5 \mathrm{~s} \times 512$ increments), corresponding to a sensitivity of $1.9 \mathrm{~min}^{-1 / 2}$ (Fig. 3B). However, the positive projection of the 2D D-HMQC spectrum had a SNR of $c a .83$ and sensitivity of $7.2 \mathrm{~min}^{-1 / 2}$ (Fig. 3C). This analysis indicates $\alpha^{1 / 2} \approx 15$ (for a single column of the $2 \mathrm{D}$ ) and $\alpha^{1 / 2} \approx 4$ (for the positive projection). The measured values of $\alpha$ directly include additional losses in sensitivity from $t_{1}$-noise since the SNR of the indirectly detected ${ }^{195} \mathrm{Pt}$ spectrum was measured. Therefore, for the full 2D D-HMQC experiment with eqn (1) we estimate $\xi$ is between 22 and 82 .

Fig. 3 shows direct comparisons of indirectly detected MAS ${ }^{195} \mathrm{Pt}$ spectra obtained from the 2D D-HMQC spectrum (Fig. 1B) and $1 \mathrm{D}$ direct detection MAS ${ }^{195} \mathrm{Pt}$ solid-state NMR spectra of cisplatin obtained with Bloch decay and RESPIRATION-CP pulse sequences. After 34.1 hours of acquisition (1024 scans $\times 120 \mathrm{~s}$ ) the Bloch decay spectrum has a SNR of 8 , corresponding to a sensitivity of $0.18 \mathrm{~min}^{-1 / 2}$ (Fig. 3D). Comparison of the sensitivity of the Bloch decay spectrum and the $1 \mathrm{D}{ }^{1} \mathrm{H}-{ }^{195} \mathrm{Pt} \mathrm{D}-\mathrm{HMQC}$ spectrum (Fig. 2C) obtained with an optimal $14.8 \mathrm{~s}$ recycle delay results in a $\xi$ of $c a$. 467. Comparison to the $2 \mathrm{D}^{1} \mathrm{H}^{1}{ }^{195} \mathrm{Pt} \mathrm{D}-\mathrm{HMQC}$ spectrum results in $\xi$ of 10 and 40 if the most intense column or the positive projection of the $2 \mathrm{D}$ spectrum are used, respectively. Note that the $0.5 \mathrm{~s}$ recycle delay that was used for acquisition of the $2 \mathrm{D}$ spectrum is far less than the optimal value of $14.8 \mathrm{~s}$. The sensitivity of the 2D D-HMQC spectrum and $\xi$ could potentially be increased by a factor of $c a$. 3 with use of the much longer optimal recycle delay (at the expense of a much longer experiment time). Therefore, the measured values of $\xi$ are consistent with those estimated using eqn (1).

A wideline CPMAS ${ }^{1} \mathrm{H}-{ }^{195} \mathrm{Pt}$ solid-state NMR spectrum of cisplatin was also obtained with RESPIRATION-CP (Fig. 3E). ${ }^{74}$ The RESPIRATION-CP pulse sequence has previously been applied to obtain wideline CPMAS ${ }^{1} \mathrm{H}^{-}{ }^{14} \mathrm{~N}$ and ${ }^{1} \mathrm{H}-{ }^{2} \mathrm{H}$ solid-state NMR spectra. ${ }^{76,77}$ Note that application of the RESPIRATION-CP pulse sequence requires prior knowledge of the peak positions since the carrier frequency for the $\theta$ pulses on the hetero-nucleus must be within a few $\mathrm{kHz}$ of an isotropic or sideband peak. ${ }^{74,76,77}$ After 8.2 hours $(2000$ scans $\times 14.8 \mathrm{~s})$ the RESPIRATION-CP

\section{(A) Analytical Simulation}
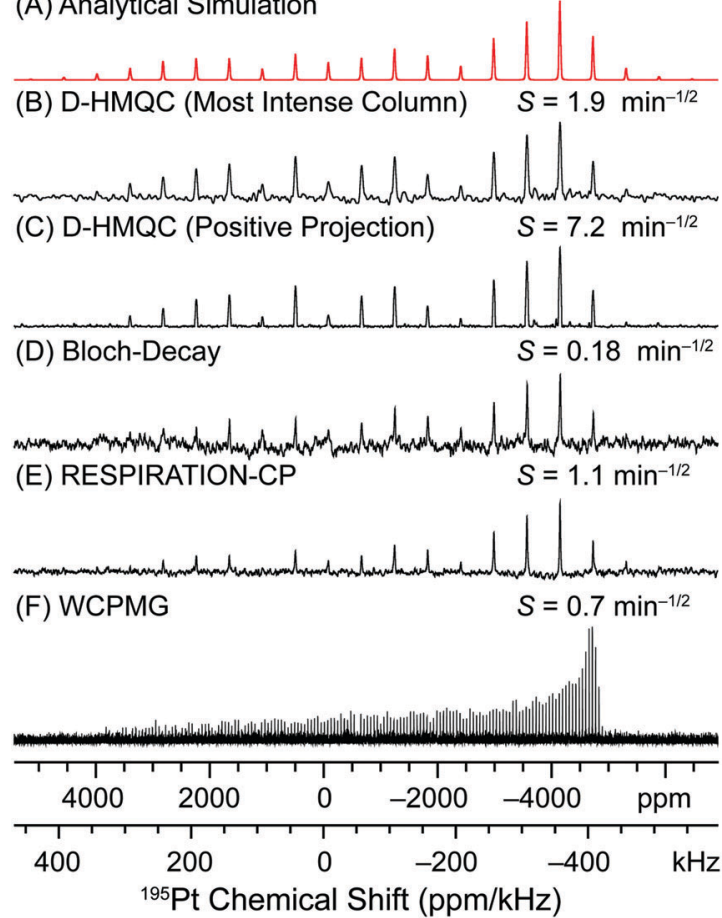

Fig. 3 Comparison of ${ }^{1} \mathrm{H}$ detected and ${ }^{195} \mathrm{Pt}$ detected solid-state NMR spectra of cisplatin. The sensitivity $\left[S=S N R /\left(\right.\right.$ time $\left.\left.^{1 / 2}\right)\right]$ is indicated above each spectrum. All MAS experiments were performed with a $50 \mathrm{kHz}$ MAS frequency. (A) Analytical simulation of the MAS ${ }^{195} \mathrm{Pt}$ solid-state NMR spectrum with $\delta_{\text {iso }}=-1834 \mathrm{ppm}, \Omega=8975 \mathrm{ppm}$ and $\kappa=-0.96$. (B and C) MAS ${ }^{195} \mathrm{Pt}$ NMR spectra obtained from the most intense column and the positive projection of the 2D D-HMQC spectrum presented in Fig. 1B (acquired in 2.3 hours). (D) MAS direct excitation ${ }^{195} \mathrm{Pt}$ Bloch decay NMR spectrum obtained with 1024 scans and a 120 s recycle delay (34.1 hours). (E) ${ }^{1} \mathrm{H}-{ }^{195} \mathrm{Pt}$ RESPIRATION-CPMAS spectrum obtained with 2000 scans and a 14.8 s recycle delay ( 8.2 hours). (F) Direct excitation ${ }^{195} \mathrm{Pt}$ WCPMG static NMR spectrum obtained with 680 scans and a 120 s delay (22.7 hours).

spectrum had a SNR of 25, corresponding to a sensitivity of $1.1 \mathrm{~min}^{-1 / 2}$. Comparison of the sensitivity of RESPIRATION-CP to that of the $1 \mathrm{D}^{1} \mathrm{H}-{ }^{195} \mathrm{Pt} \mathrm{D}-\mathrm{HMQC}$ gives $\xi \approx 75$ and comparison to 
the $2 \mathrm{D}{ }^{1} \mathrm{H}^{195} \mathrm{Pt}$ D-HMQC gives $\xi \approx 1.7$ or 6.5 depending if a single column or the positive projection is considered. If ${ }^{1} \mathrm{H}$ detected ${ }^{1} \mathrm{H}-{ }^{195} \mathrm{Pt}$ D-HMQC and ${ }^{195} \mathrm{Pt}$ detected ${ }^{1} \mathrm{H}-{ }^{195} \mathrm{Pt}$ CPMAS NMR spectra are compared then eqn (1) should be modified so that the ratio of $\gamma$ term is raised to the power $3 / 2$ (instead of 5/2) and the $T_{1}$ term should be eliminated since both experiments use the ${ }^{1} \mathrm{H} T_{1}$. This reduces the maximum estimated $\xi$ by factors of 14 and this is consistent with the reduced $\xi$ observed when comparing the D-HMQC and RESPIRATION-CP spectra.

Finally, a static ${ }^{195} \mathrm{Pt}$ solid-state NMR spectrum of cisplatin was acquired with direct excitation and the WCPMG pulse sequence (Fig. 3F). With WCPMG the entire ${ }^{195} \mathrm{Pt}$ powder pattern was obtained in a single transmitter offset since the $1.3 \mathrm{~mm} \mathrm{HX}$ probe had a large excitation/receiving bandwidth. The static ${ }^{195} \mathrm{Pt}$ WCPMG NMR spectrum of cisplatin had a signal to noise ratio (SNR) of 27 after a total experiment time of 22.7 hours ( 680 scans $\times$ $120 \mathrm{~s}$ delay), corresponding to a sensitivity of $0.7 \mathrm{~min}^{-1 / 2}$. Comparison of the static WCPMG spectrum and the indirectly detected ${ }^{1} \mathrm{H}^{-195} \mathrm{Pt}$ D-HMQC illustrates that D-HMQC simultaneously gives the best sensitivity and provides informative, high resolution 2D NMR spectra.

\section{Measuring ${ }^{195} \mathrm{Pt}$ CS tensor parameters}

The ${ }^{195} \mathrm{Pt}$ MAS NMR sideband manifold of cisplatin extracted from the projection of the indirect dimension of the 2D D-HMQC spectrum is shown in Fig. 1C along with an analytical simulation which used the previously published ${ }^{195} \mathrm{Pt}$ CS tensors for cisplatin (green trace (isotropic chemical shift) $\delta_{\text {iso }}=-1834 \mathrm{ppm}$; $\Omega=8975 \mathrm{ppm}$, (skew) $\kappa=-0.96) .{ }^{43}$ Comparison of the analytical simulations and experimentally measured, indirectly detected sideband manifold shows all of the expected sidebands are present, without a significant reduction in the relative intensity of the outer sidebands. An analytical fit of the observed sideband manifold yields very similar CS tensor parameters with a slightly lower value of $\Omega$ obtained (red trace, $\delta_{\text {iso }}=-1834 \mathrm{ppm} ; \Omega=8561 \mathrm{ppm}$, $\kappa=-0.96)$. This illustrates that the broad sideband manifold which covers $c a .800 \mathrm{kHz}$ can be uniformly excited. This is possible because the $1.3 \mathrm{~mm}$ probe used for the experiments is equipped with a small diameter solenoid coil that provides very high $\mathrm{rf}$ fields. A ${ }^{195} \mathrm{Pt}$ rf field of $c a .278 \mathrm{kHz}$ corresponding to a ${ }^{195} \mathrm{Pt} \pi / 2$ pulse width of $0.9 \mu$ s could be obtained with $160 \mathrm{~W}$ of input power.

Numerical simulations indicate that with a $278 \mathrm{kHz}$ rf field it is possible to excite and detect a broad range of isotropic chemical shifts (Fig. S3A, ESI $\dagger$ ). Excitation bandwidths can be significantly increased at the expense of efficiency if smaller tip angle pulses are used. Numerical simulation of the D-HMQC experiment for ${ }^{195} \mathrm{Pt}$ sites with different $\Omega$ indicate that $\theta$ pulses with tip angles less than $90^{\circ}$ provide the largest D-HMQC signal for ${ }^{195} \mathrm{Pt}$ sites with large $\Omega$ (Fig. S3B, ESI $\dagger$ ). Note that sites with different $\Omega$ also show different D-HMQC efficiencies and different oscillation/nutation with the $\theta$ pulse tip angle. For sites with large $\Omega$, the there is good agreement between the simulated and experimentally observed variation in the D-HMQC signal of transplatin with the $\theta$ pulse tip angle (Fig. S3C, ESI $\dagger$ ). Finally, comparison of simulations of the experimental, indirectly detected wideline MAS ${ }^{195} \mathrm{Pt}$ sideband manifold of cisplatin to a numerical simulation confirms that with these conditions the wideline spinning sideband manifold is uniformly excited (Fig. S3D, ESI $\dagger$ ). While conventional pulses worked well here, alternative excitation pulses and schemes can possibly further improve excitation bandwidths in HMQC pulse sequences. ${ }^{71,78}$

2D ${ }^{1} \mathrm{H}^{1}{ }^{195} \mathrm{Pt}$ D-HMQC spectra of transplatin were acquired with total experiment times of 1.7 hours and 3.0 hours with MAS frequencies of $50 \mathrm{kHz}$ and $40 \mathrm{kHz}$, respectively (Fig. 4). Note that these short total acquisition times were possible despite the fact that an unfavorable ${ }^{1} \mathrm{H} T_{1}$ of $17 \mathrm{~s}$ was measured for transplatin. For both MAS frequencies, a high SNR, uniformly excited wideline MAS ${ }^{195} \mathrm{Pt}$ solid-state NMR spectrum was once again obtained. We note that Lucier et al. previously acquired a Bloch decay MAS ${ }^{195} \mathrm{Pt}$ NMR spectrum of transplatin with a similar or lower signal to noise ratios compared to the indirectly detected spectra presented here. However, an experiment time of $c a .20$ hours was required with a MAS frequency of $26 \mathrm{kHz}$ and a larger $2.5 \mathrm{~mm}$ rotor. ${ }^{43}$ This again highlights the large gains in absolute sensitivity that can be obtained with ${ }^{1} \mathrm{H}$ detected D-HMQC experiments. Analytical fits of the indirectly detected MAS wideline sideband manifolds once again yield good agreement with the previously published CS tensor parameters and demonstrate uniform excitation of the sideband manifold (Fig. 4).

\section{Detecting Pt containing impurities with ${ }^{1} \mathrm{H}-{ }^{195} \mathrm{Pt}$ D-HMQC}

During the course of this work ${ }^{1} \mathrm{H}^{-195} \mathrm{Pt} \mathrm{D}-\mathrm{HMQC}$ experiments were also conducted on different samples of cisplatin and transplatin obtained from Sigma Aldrich (Fig. S4, ESI $\dagger$ ). This second cisplatin sample showed the presence of several other platinum sites/sideband manifolds with relatively low intensities in the $2 \mathrm{D}{ }^{1} \mathrm{H}-{ }^{195} \mathrm{Pt}$ D-HMQC spectrum (Fig. S4, ESI $\dagger$ ). Note that these other sites also give rise to very broad MAS sideband manifolds which cover a similar frequency range to the cisplatin manifold. These other impurity sites would therefore be challenging or impossible to detect in static experiments. The sample of transplatin from Sigma Aldrich showed the presence of an impurity which must possess an octahedral Pt coordination environment given the much smaller $\Omega$ and $\delta_{\text {iso }}$ closer to 0 ppm for this site (Fig. S4, ESI $\dagger$ ). The intensity of the signals from the octahedral Pt impurity are strongly amplified in the $2 \mathrm{D}{ }^{1} \mathrm{H}-{ }^{195} \mathrm{Pt}$ D-HMQC spectrum since the site has a small CSA and all intensity is focused into the isotropic peak. We also note that there were several different spinning sideband manifolds and isotropic chemical shifts which were similar in appearance and position, but not the same as that observed in the Alfa Aesar sample of transplatin. This could indicate that there are polymorphs of transplatin or other impurities present in the second sample of transplatin, however, additional experiments beyond the scope of this work are needed to definitively test this hypothesis. These examples demonstrate the advantages of $2 \mathrm{D}{ }^{1} \mathrm{H}-{ }^{195} \mathrm{Pt}$ D-HQMC experiments for resolving different Pt sites and detecting dilute Pt containing impurities/phases.

\section{Indirect detection of MAS wideline solid-state NMR spectra of quadrupolar nuclei}

Quadrupolar nuclei (nuclear spin $I>1 / 2$ ) frequently give rise to solid-state NMR spectra which are significantly broadened by the 
(A)

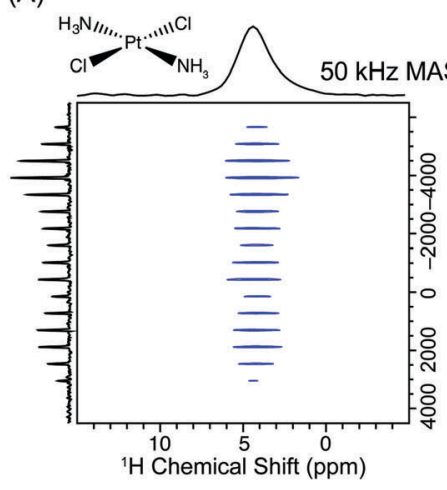

(B)

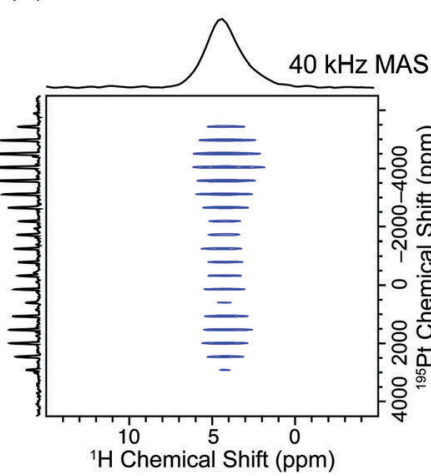

(C) $40 \mathrm{kHz}$ MAS

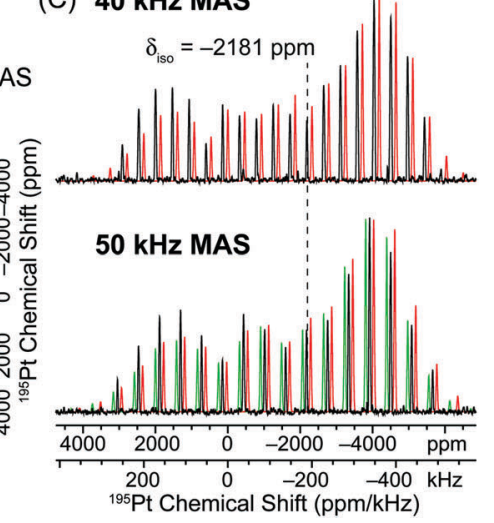

Fig. 4 (A) $2 \mathrm{D}^{1} \mathrm{H}-{ }^{195} \mathrm{Pt} \mathrm{D}-\mathrm{HMQC}$ correlation spectrum of transplatin (Alfa Aesar) acquired with a $50 \mathrm{kHz}$ MAS frequency, $32 \mathrm{scans}$ per increment, a $0.5 \mathrm{~s}$ recycle delay, $m=27\left(2 \mathrm{~m} \times \tau_{\mathrm{r}}=1.08 \mathrm{~ms}\right), n=6\left(n \times \tau_{\mathrm{r}}=120 \mu \mathrm{s}\right), 380$ individual $t_{1}$ increments and $t_{1}$ was incremented in steps of $0.8 \mu \mathrm{s}(1.25 \mathrm{MHz}$ indirect dimension spectral width). The total experiment time was 1.7 hours. (B) $2 \mathrm{D}^{1} \mathrm{H}-{ }^{195} \mathrm{Pt} \mathrm{D}-\mathrm{HMQC}$ correlation spectrum acquired with an MAS frequency of $40 \mathrm{kHz}, 32$ scans per increment, a $1.0 \mathrm{~s}$ recycle delay, $m=27\left(2 m \times \tau_{\mathrm{r}}=1.35 \mathrm{~ms}\right), n=5\left(n \times \tau_{\mathrm{r}}=125 \mu \mathrm{s}\right), 336$ individual $t_{1}$ increments and $t_{1}$ was incremented in steps of $0.8 \mu \mathrm{s}(1.25 \mathrm{MHz}$ indirect dimension spectral width). The total experiment time was 3.0 hours. In both (A) and (B) $\theta$ pulses $0.6 \mu$ in duration with a $278 \mathrm{kHz}$ rf field $\left(60^{\circ}\right.$ tip angle) were used for excitation/reconversion of the ${ }^{195} \mathrm{Pt}$ signal. (C) The positive projections of the indirectly detected ${ }^{195} \mathrm{Pt}$ dimension from the $40 \mathrm{kHz}$ (upper set) and $50 \mathrm{kHz}$ MAS frequency (lower set) D-HMQC spectra (black traces) are compared to analytical simulations/fits. For the $50 \mathrm{kHz}$ MAS D-HMQC spectrum an analytical simulation was performed with the previously reported values of $\Omega$ and $\kappa$ (green trace $\left.\delta_{\text {iso }}=-2181 \mathrm{ppm} ; \Omega=9100 \mathrm{ppm}, \kappa=-0.60\right) .{ }^{28}$ An analytical fit of the $50 \mathrm{kHz}$ MAS sideband manifold yielded similar CS tensor parameters (lower red trace, $\left.\delta_{\text {iso }}=-2181 \mathrm{ppm} ; \Omega=8850 \mathrm{ppm}, \kappa=-0.64\right)$. The analytical fit of the $40 \mathrm{kHz}$ MAS sideband manifold yielded similar CS tensor parameters to those determined from the $50 \mathrm{kHz}$ MAS sideband manifold (upper red trace, $\delta_{\text {iso }}=-2185 \mathrm{ppm} ; \Omega=9001 \mathrm{ppm}, \kappa=-0.63$ ). The simulated sideband manifolds were offset from the experimental one to allow better comparison of sideband intensities.

quadrupolar interaction (QI), and in some cases by the combined effects of the QI and CSA. ${ }^{9-11}$ By fitting static and MAS solid-state NMR spectra of the central or satellite transitions of quadrupolar nuclei it is possible to measure the EFG tensor parameters: the quadrupolar coupling constant $\left(C_{\mathrm{Q}}\right)$ and the EFG tensor asymmetry parameter $\left(\eta_{\mathrm{Q}}\right) . C_{\mathrm{Q}}$ depends upon the magnitude of the EFG at the nuclear site which is determined by the degree of spherical symmetry at the nuclear site; highly spherically symmetric coordination environments give rise to negligible $C_{\mathrm{Q}}$ and minimal broadening, while asymmetric sites will possess large $C_{\mathrm{Q}}$ and give rise to very broad solid-state NMR spectra. The presence or absence of rotational symmetry axes at the nuclear site will give rise to extreme values of $\eta_{\mathrm{Q}}$ of 0 and 1. Measurement of the EFG tensor parameters serves as a powerful probe of bonding, structure and dynamics. ${ }^{10,11,79-85}$

Application of MAS to integer spin quadrupolar nuclei (e.g., ${ }^{2} \mathrm{H}$ and ${ }^{14} \mathrm{~N}$ ) typically results in relatively narrow peaks and a broad manifold of spinning sidebands, which is reminiscent of the MAS NMR spectrum of a spin-1/2 nucleus subjected to large CSA. However, the intensity of the sidebands and symmetry of the sideband manifold are determined by the EFG tensor parameters, $C_{\mathrm{Q}}$ and $\eta_{\mathrm{Q}}$. HMQC pulse sequences with rotor synchronized indirect dimensions have been extensively applied to indirectly detect single quantum, double quantum and overtone MAS ${ }^{14} \mathrm{~N}$ solid-state NMR spectra. ${ }^{57-59,86-88}$ Constant time HMQC with large indirect spectral widths could potentially be used to indirectly detect the broad manifolds of spinning sidebands seen in the MAS NMR spectra of integer spin quadrupolar nuclei. However, here we focus on indirect detection of MAS wideline NMR spectra of halfinteger quadrupolar nuclei.

Application of MAS to half-integer quadrupolar nuclei results in only a partial narrowing of the NMR spectrum since MAS cannot fully average the broadening of the central transition (CT) or satellite transitions (STs) by the second-order QI. It is important to note that for half-integer quadrupolar nuclei, usually only the central transition (CT) is observed since STs are substantially broadened by the first-order QI. Since the CT is usually inhomogeneously broadened by the second-order QI, CPMG pulse sequences are often applied for signal enhancement of both static and MAS solid-state NMR spectra. ${ }^{34,35,40}$ Here we demonstrate that D-HMQC can also be applied to indirectly detect wideline MAS solid-state NMR spectra of half-integer quadrupolar nuclei.

Fig. 5 shows MAS and static ${ }^{71}$ Ga solid-state NMR spectra of a gallium acetate hydroxide coordination complex with an empirical molecular formula of $\mathrm{Ga}(\mathrm{OH})_{2}\left(\mathrm{CH}_{3} \mathrm{CO}_{2}\right)(\mathbf{1})$. The absolute solid-state structure of $\mathbf{1}$ is yet to be confirmed, however, this complex is likely a self-assembled coordination polymer, i.e., $\left[\mathrm{Ga}(\mathrm{OH})_{2}\left(\mathrm{CH}_{3} \mathrm{CO}_{2}\right)\right]_{m}$. All Ga ions are likely equivalent and reside in distorted octahedral coordination environments which are formed by bridging hydroxide and acetate ligands. For the purposes of this work the structural details are unimportant, but a more complete investigation of the solid-state structure will be described in a forthcoming publication. ${ }^{89}$ The static ${ }^{71} \mathrm{Ga}$ solid-state NMR spectrum of $\mathbf{1}$ is substantially broadened by the second-order QI, resulting in a ${ }^{71} \mathrm{Ga} C \mathrm{CT}$ powder pattern which covers a frequency range of $c a .380 \mathrm{kHz}$ (Fig. 5A). This indicates that there is a large EFG at the Ga site, which is consistent with a distorted octahedral Ga coordination environment in 1. A static ${ }^{71} \mathrm{Ga}$ solid-state NMR spectrum with a SNR of 41 (sensitivity = $14.1 \mathrm{~min}^{-1 / 2}$ ) was acquired with the WCPMG pulse sequence ${ }^{38}$ and a single transmitter offset. The static ${ }^{71} \mathrm{Ga}$ WCPMG NMR spectrum was obtained in only 8.5 minutes due to the favorable combination of a short ${ }^{71} \mathrm{Ga} T_{1}$ (a $0.5 \mathrm{~s}$ recycle delay was used) 

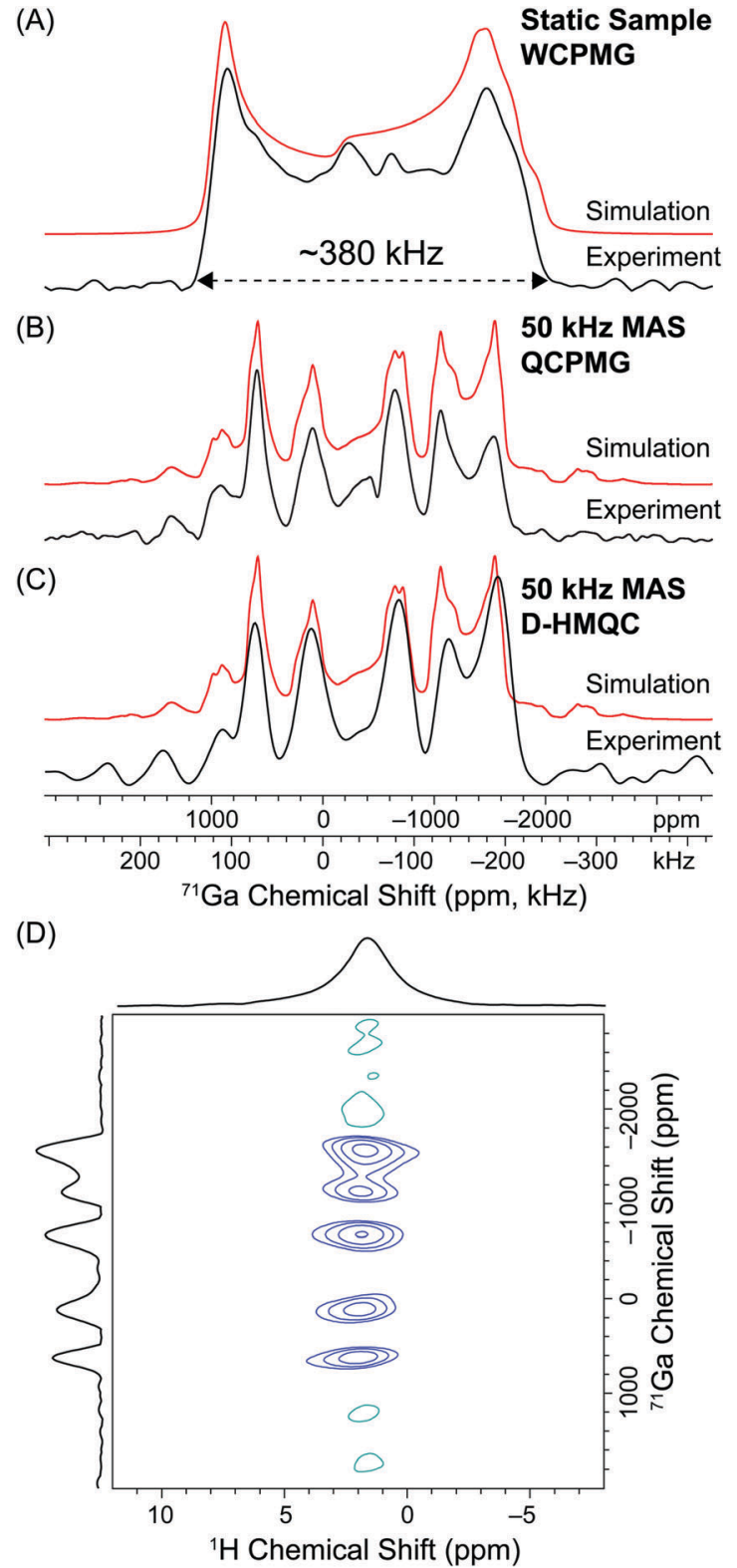

Fig. 5 (A) Static ${ }^{71} \mathrm{Ga}$ solid-state NMR spectrum of 1 obtained with the WCPMG pulse sequence. Total experiment time was 8.5 minutes (1024 scans, $0.5 \mathrm{~s}$ recycle delay). (B) $50 \mathrm{kHz}$ MAS ${ }^{71} \mathrm{Ga}$ solid-state NMR spectrum of 1 acquired with the QCPMG pulse sequence. The total experiment time was 9.4 minutes (1128 scans, $0.5 \mathrm{~s}$ recycle delay). (C) $50 \mathrm{kHz}$ MAS ${ }^{71} \mathrm{Ga}$ solid-state NMR spectrum obtained from the indirect dimension of the 2D ${ }^{1} \mathrm{H}-{ }^{71} \mathrm{Ga} \mathrm{D}-\mathrm{HMQC}$ spectrum at a ${ }^{1} \mathrm{H}$ chemical shift of $1.8 \mathrm{ppm}$. (D) 2D ${ }^{1} \mathrm{H}-{ }^{71} \mathrm{Ga} D-H M Q C$ spectrum acquired with an MAS frequency of $50 \mathrm{kHz}$, 32 scans per increment, a $1.0 \mathrm{~s}$ recycle delay, $m=16\left(2 \mathrm{~m} \times \tau_{\mathrm{r}}=640 \mu \mathrm{s}\right)$, $n=3\left(n \times \tau_{r}=60 \mu \mathrm{s}\right), 80$ individual $t_{1}$ increments and $t_{1}$ was incremented in steps of $1.25 \mu \mathrm{s}$ ( $800 \mathrm{kHz}$ indirect dimension spectral width). $0.61 \mu \mathrm{s} \pi / 2 \mathrm{CT}$ selective pulses were used for excitation/reconversion of the ${ }^{71} \mathrm{Ga}$ signal. The total experiment time was 43 minutes. Analytical simulations are shown above the experimental spectra (red traces) and EFG and CS tensor parameters are given in the ESI. $\dagger$

and long ${ }^{71} \mathrm{Ga} T_{2}$ (60 spin echoes were acquired over $14 \mathrm{~ms}$ ). The static ${ }^{71}$ Ga NMR spectrum can readily be simulated to determine the ${ }^{71} \mathrm{Ga}$ EFG tensor parameters $\left(C_{\mathrm{Q}}\right.$ and $\left.\eta_{\mathrm{Q}}\right)$ and estimate the
CS tensor parameters (Fig. 5A). These parameters are given in the $\mathrm{ESI} \dagger$ (Table S1).

A $50 \mathrm{kHz}$ MAS ${ }^{71} \mathrm{Ga}$ solid-state NMR spectrum with a SNR of 45 was acquired in 9.4 minutes (sensitivity $=14.7 \mathrm{~min}^{-1 / 2}$ ) with a rotor-synchronized QCPMG pulse sequence (Fig. 5B). For MAS experiments on half-integer quadrupolar nuclei, the MAS frequency must be greater than the width of the isotropic MAS NMR CT powder pattern to avoid spinning sideband overlap. Here the MAS frequency is not fast enough to avoid overlap of the broad isotropic ${ }^{71} \mathrm{Ga}$ CT powder pattern with its own broad spinning sidebands. At this applied magnetic field a MAS frequency $>120 \mathrm{kHz}$ would be required to obtain a "clean" isotropic MAS CT ${ }^{71} \mathrm{Ga}$ powder pattern free of sideband overlap. Subsequently, the $50 \mathrm{kHz}$ MAS ${ }^{71} \mathrm{Ga}$ solidstate NMR spectrum of 1 consists of an isotropic MAS CT powder pattern overlapping with its own sidebands. The resulting spectrum is referred to as an "intermediate MAS NMR spectrum". At first sight the resulting intermediate MAS NMR spectrum of 1 appears to be much more complicated than the corresponding static spectrum since there are now several discontinuities. However, note that the breadth of the intermediate MAS NMR spectrum is essentially the same as that of the static NMR spectrum. It is therefore possible to easily estimate the magnitude of $C_{\mathrm{Q}}$ simply by comparing the breadths of the intermediate MAS NMR spectrum to that of a simulated static solid-state NMR spectrum. Furthermore, the intermediate MAS NMR spectrum can be readily fit with established simulation software packages in order to directly determine $C_{\mathrm{Q}}$ and $\eta_{\mathrm{Q}}$ with reasonable accuracy (Fig. 5B).

Fig. 5C shows the indirectly detected intermediate MAS ${ }^{71} \mathrm{Ga}$ solid-state NMR spectrum of $1\left(\mathrm{SNR}=15\right.$, sensitivity $\left.=2.3 \mathrm{~min}^{-1 / 2}\right)$ obtained from the $2 \mathrm{D}{ }^{1} \mathrm{H}-{ }^{71} \mathrm{Ga}$ D-HMQC correlation spectrum acquired with a MAS frequency of $50 \mathrm{kHz}$ (Fig. 5D). The 2D ${ }^{1} \mathrm{H}-{ }^{71} \mathrm{Ga}$ D-HMQC spectrum correlates the ${ }^{1} \mathrm{H}$ nuclei of the acetate/hydroxide ligands to the wideline intermediate MAS ${ }^{71} \mathrm{Ga}$ solid-state NMR spectrum. The $2 \mathrm{D}{ }^{1} \mathrm{H}-{ }^{71} \mathrm{Ga}$ D-HMQC spectrum was acquired in a total experiment time of 43 minutes which is $c a$. 4-5 times longer than the time required for the directly detected static or MAS ${ }^{71}$ Ga QCPMG NMR experiments. ${ }^{71} \mathrm{Ga}$ has a relatively high gyromagnetic ratio $\left(\gamma_{1_{\mathrm{H}}} / \gamma_{7_{1} \mathrm{Ga}}=3.28\right)$ and a nuclear spin of $I=3 / 2$. Subsequently the magnetic moment $(\mu)$ of ${ }^{1} \mathrm{H}$ is only ca. 1.5 times larger than that of ${ }^{71} \mathrm{Ga}$. Indirect ${ }^{1} \mathrm{H}$ detection can provide a sensitivity gain of at most $c a$. 8.7 considering only $\gamma$ and $\mu$. Furthermore, direct ${ }^{71} \mathrm{Ga}$ WCPMG and QCPMG experiments are very efficient for 1 because the ${ }^{71} \mathrm{Ga}$ $T_{1}$ is short and the ${ }^{71} \mathrm{Ga} T_{2}{ }^{\prime}$ is long. For quadrupolar nuclei with relatively high $\gamma$ and/or high nuclear spin, proton detection with D-HMQC is unlikely to provide a net gain in sensitivity compared to CPMG techniques. Indeed, here we obtain approximately 7 times higher sensitivity with direct detection CPMG for ${ }^{71} \mathrm{Ga}$ solid-state NMR experiments on $\mathbf{1}$.

However, the indirectly detected MAS ${ }^{71} \mathrm{Ga}$ solid-state NMR spectrum is very similar in appearance to the directly detected intermediate MAS spectrum. The $2 \mathrm{D}^{1} \mathrm{H}-{ }^{71} \mathrm{Ga}$ D-HMQC spectrum has the advantage that dispersion of the signals into two dimensions can potentially resolve overlapping intermediate MAS sideband patterns by obtaining correlations to different peaks in the higher resolution ${ }^{1} \mathrm{H}$ dimension. The $2 \mathrm{D}$ spectrum also 
enables the spatial proximities of the metal center and the ${ }^{1} \mathrm{H}$ nuclei of the ligands to be confirmed.

\section{Conclusions}

In conclusion we have demonstrated that fast MAS ${ }^{1} \mathrm{H}$-detected D-HMQC experiments enables the rapid acquisition of wideline MAS solid-state NMR spectra of both spin-1/2 and quadrupolar nuclei. D-HMQC is a promising alternative to CPMG techniques for the acquisition of wideline solid-state NMR spectra of spin-1/2 and quadrupolar nuclei. By employing a simple constant time D-HMQC pulse sequence, arbitrary indirect dimension spectral widths can be easily used. This enabled the wideline MAS solidstate NMR spectrum to be detected in the indirect dimension of the 2D correlation spectrum. The D-HMQC pulse sequence is ideally suited for indirect detection of wideline MAS solid-state NMR spectra because it provides efficient, broadband coherence transfer between ${ }^{1} \mathrm{H}$ and the hetero-nucleus and a large gain in sensitivity from proton detection. D-HMQC enabled rapid acquisition of $2 \mathrm{D}^{1} \mathrm{H}^{-}{ }^{195} \mathrm{Pt}$ correlation sold-state NMR spectra of cisplatin and transplatin in experiment times of $c a$. 2 hours. Comparison of ${ }^{195} \mathrm{Pt}$ solid-state NMR spectra obtained with direct detection and the ${ }^{1} \mathrm{H}$ detected 2D D-HMQC spectrum demonstrate that indirect detection provides sensitivity gains between 1 to 2 orders of magnitude. $2 \mathrm{D}{ }^{1} \mathrm{H}^{-71} \mathrm{Ga}$ D-HMQC experiments required slightly longer experiment time than direct detection MAS and static CPMG experiments. However, the 2D NMR spectrum offers the advantage that overlapping sites could potentially be resolved by correlation to different ${ }^{1} \mathrm{H}$ chemical shifts. This would be similar to the way in which overlapping MAS quadrupolar NMR powder patterns correlated to isotropic chemical shifts are resolved in an MQMAS experiment. In this regard high magnetic fields would obviously be very advantageous for experiments with half-integer quadrupolar nuclei since the ${ }^{1} \mathrm{H}$ chemical shift dispersion would increase and simultaneously the breadth of the quadrupolar NMR powder pattern would decrease.

One key drawback of the D-HMQC pulse sequence is that both the MAS frequency and spectrometer must be very stable to avoid excessive $t_{1}$-noise because the signals from uncoupled ${ }^{1} \mathrm{H}$ spins are imperfectly suppressed by phase cycling alone. ${ }^{62,65,90,91}$ Therefore, this method may not be applicable to isotopes with very low abundance, when the hetero-nuclei are dilute or when there are multiple overlapping ${ }^{1} \mathrm{H}$ signals. However, this method should be generally applicable for the rapid indirect detection of $2 \mathrm{D}$ solidstate NMR dipolar correlation spectra of a wide variety of moderately abundant spin-1/2 and quadrupolar nuclei that give rise to wideline solid-state NMR spectra or in cases where there are multiple isotropic spin-1/2 signals with large frequency differences. These experiments will likely benefit from the development of probe technology that provide faster MAS rates and larger rf fields.

\section{Experimental}

Samples of cisplatin and transplatin were purchased from Alfa Aesar (solid-state NMR spectra shown in Fig. 1-4) and Sigma
Aldrich (solid-state NMR spectra shown in Fig. S4, ESI $†$ ) and used without further purification. The Ga coordination polymer $\mathbf{1}$ was prepared in the following way: eutectic gallium-indium metal particles were prepared by the SLICE technique. ${ }^{92}$ Treatment of the eutectic gallium-indium metal particles with acetic acid under ambient conditions lead to the etching of $\mathrm{Ga}$ from the passivating oxide layer. 1 was then observed to precipitate in situ as a white powder which consisted of high aspect ratio nanobeams. The synthesis, composition, structure and properties of $\mathbf{1}$ will be described in detail in a forthcoming publication. ${ }^{89}$

All solid-state NMR experiments were performed on a Bruker wide-bore $9.4 \mathrm{~T}\left(\nu_{0}\left({ }^{1} \mathrm{H}\right)=400 \mathrm{MHz}\right) \mathrm{NMR}$ spectrometer equipped with a Bruker Avance III HD console and a Bruker $1.3 \mathrm{~mm}$ broadband HX fast MAS probe. ${ }^{195} \mathrm{Pt}$ rf pulses were calibrated on the ${ }^{127} \mathrm{I}$ resonance of potassium iodide. ${ }^{71} \mathrm{Ga}$ rf pulses were calibrated on an aqueous solution of $\mathrm{GaCl}_{3}$ and for solid-state NMR experiments the solution NMR pulse widths were divided by a factor 2 to obtain CT selective pulse widths. ${ }^{1} \mathrm{H}$ rf pulses were directly calibrated on the samples of interest. ${ }^{1} \mathrm{H}$ chemical shifts were referenced to neat tetramethylsilane by the use of adamantane $\left(\delta_{\text {iso }}\left({ }^{1} \mathrm{H}\right)=1.82 \mathrm{ppm}\right)$ as a secondary chemical shift standard. ${ }^{195} \mathrm{Pt}$ and ${ }^{71} \mathrm{Ga}$ chemical shifts were indirectly referenced to the established chemical shift standards using the previously published relative NMR frequencies. ${ }^{72}$

D-HMQC experiments were performed with the previously described pulse sequence ${ }^{60-65}$ However, as described in the main text, rather than simultaneously incrementing the central spin echo block and $t_{1}$ evolution period, the central spin echo block was fixed to a constant time period and the $\theta$ pulses were incremented outwards during the $2 \mathrm{D}$ experiments. In all D-HMQC experiments the symmetry based recoupling sequence supercycled (S)R $4_{1}^{2},{ }^{73}$ was applied to the ${ }^{1} \mathrm{H}$ nuclei for a fixed duration in order to build-up and re-convert anti-phase coherence $\left(\mathrm{I}_{x} \mathrm{~S}_{z}\right)$ via hetero-nuclear dipolar couplings. ${ }^{60,61}$ We note that other recoupling schemes are also available. ${ }^{61}$ In all cases the rf field for $\mathrm{SR} 4_{1}^{2}$ was set to two times the sample spinning rate to fulfill the second order rotary resonance recoupling $\left(\mathrm{R}^{3}\right)$ condition. The second order $\mathrm{R}^{3}$ condition was precisely calibrated by performing a ${ }^{1} \mathrm{H} 90^{\circ}$ pulse-spin lock pulse sequence with the spin lock pulse power varied around the value previously calibrated for a $100 \mathrm{kHz}$ rf field..$^{93}$ The precise spin lock pulse power leading to the lowest observable ${ }^{1} \mathrm{H}$ NMR signal was then utilized. ${ }^{93}$ For all D-HMQC experiments the length of the recoupling sequence was empirically optimized on the sample of interest and the recoupling time providing the largest signal was used. For experiments on ${ }^{195} \mathrm{Pt}$ the $\theta$ pulse width was directly optimized on the samples and for both cisplatin and transplatin $0.6 \mu \mathrm{s} 60^{\circ}$ pulses (corresponding to a $278 \mathrm{kHz}$ rf field) were found to provide optimal signal (Fig. S3, ESI $\dagger$ ). Details on the exact experimental settings used for D-HMQC experiments (number of scans, pulse widths, number of $t_{1}$ increments, recycle delay, etc.) are provided in the figure captions and main text.

The $50 \mathrm{kHz}$ MAS Bloch decay (pulse-acquire) ${ }^{195} \mathrm{Pt}$ NMR spectrum of cisplatin was acquired with a $0.6 \mu \mathrm{s} 60^{\circ}$ excitation pulse, 1024 scans and a $120 \mathrm{~s}$ delay. Prior to Fourier transform the Bloch decay FID was shifted to the first rotational echo to 
simplify phasing of the spectrum and eliminate a broad probe background signal which was likely from the ${ }^{207} \mathrm{~Pb}$ NMR signal of lead metal. The $50 \mathrm{kHz}{ }^{1} \mathrm{H}^{-195} \mathrm{Pt}$ RESPIRATION-CPMAS ${ }^{74,76,77}$ spectrum was obtained with simultaneous rotor-synchronized $0.3 \mu \mathrm{s} \theta$ pulses with a $c a$. $160 \mathrm{kHz}$ rf field applied on both ${ }^{1} \mathrm{H}$ and ${ }^{195} \mathrm{Pt}$. The rf field of the phase alternated spin lock pulses was ca. $100 \mathrm{kHz}$ which corresponds to the second order $\mathrm{R}^{3}$ condition. The contact time was $600 \mu \mathrm{s}$ which corresponds to 30 repetitions of the RESPIRATION-CP element. The static ${ }^{195} \mathrm{Pt}$ solid-state NMR spectrum of cisplatin was obtained with the previously described WCPMG pulse sequence, ${ }^{38} 680$ scans and a 120 s recycle delay. WURST-80 pulses $25 \mu$ s in duration and sweeping across a spectral width of $1.6 \mathrm{MHz}$ were used for excitation and refocusing. The ${ }^{195} \mathrm{Pt}$ rf field was $70 \mathrm{kHz}$ for the WURST pulses.

${ }^{71} \mathrm{Ga}$ WCPMG experiments were performed with the previously described pulse sequence. ${ }^{38}$ Continuous wave ${ }^{1} \mathrm{H}$ hetero-nuclear decoupling with an rf field of $50 \mathrm{kHz}$ was applied for the duration of the static WCPMG experiments. The ${ }^{71} \mathrm{Ga}$ solid-state NMR spectrum of 1 was acquired with $25 \mu$ S WURST pulses with a total frequency sweep width of $600 \mathrm{kHz}$ and a single transmitter offset. Two static ${ }^{71} \mathrm{Ga}$ NMR spectra were acquired with WURST pulses of opposite sweep direction and were co-added. The two ${ }^{71} \mathrm{Ga}$ WCPMG NMR spectra were acquired with 512 scans, a $0.5 \mathrm{~s}$ recycle delay and 60 echoes were acquired, each of which was $100 \mu$ s duration each. The intermediate MAS ${ }^{71} \mathrm{Ga}$ solid-state NMR spectrum was acquired with an MAS frequency of $50 \mathrm{kHz}$ with a rotor synchronized QCPMG pulse sequence ${ }^{34,35}$ with 1128 scans and a $0.5 \mathrm{~s}$ recycle delay. The MAS QCPMG spectrum was acquired with $0.94 \mu \mathrm{s}$ and $1.88 \mu$ s central transition selective $\pi / 2$ and $\pi$ pulses and 40 echoes were acquired, each of which was $200 \mu \mathrm{s}$ in duration. Echo reconstructed MAS and static ${ }^{71} \mathrm{Ga}$ SSNMR spectra were formed from the CPMG spectra by co-adding each of the spin echoes in the CPMG echo-train together in the time domain, then Fourier transforming the resulting whole spin echo. ${ }^{94,95}$

Analytical simulations of static and MAS ${ }^{71} \mathrm{Ga}$ and ${ }^{195} \mathrm{Pt}$ solidstate NMR spectra were performed in the solid lineshape analysis (SOLA) module v2.2.4 included in the Bruker Topspin v3.2 software. Numerical simulations of the ${ }^{195} \mathrm{Pt}$ D-HMQC experiments (Fig. S3, $\mathrm{ESI} \dagger$ ) were performed with the SIMPSON v.4.1 software package running on a personal computer. ${ }^{96-98}$

\section{Acknowledgements}

A. J. R. thanks Iowa State University and the Ames Laboratory (Royalty Account) for support. The Ames Laboratory is operated for the U.S. DOE by Iowa State University under contract no. DE-AC02-07CH11358. M. T. acknowledges support from Iowa State University through startup funds and a Black \& Veatch Faculty Fellowship. We thank Dr Simge Çınar (Iowa State University, Materials Science and Engineering Department) for synthesizing the gallium coordination polymer. We thank Dr Luke A. O'Dell (Deakin University) for helpful comments and reading of the manuscript. We thank Dr Julien Trebosc (Université Lille) for providing initial D-HMQC pulse programs.

\section{References}

1 C. Bonhomme, C. Gervais, F. Babonneau, C. Coelho, F. Pourpoint, T. Azaïs, S. E. Ashbrook, J. M. Griffin, J. R. Yates, F. Mauri and C. J. Pickard, Chem. Rev., 2012, 112, 5733-5779.

2 Special Issue "Frontiers in Solid State NMR Technology", Acc. Chem. Res., 2013, 46.

3 Special Issue on Solid-State NMR Spectroscopy, Phys. Chem. Chem. Phys., 2009, 11.

4 D. D. Laws, H. M. L. Bitter and A. Jerschow, Angew. Chem., Int. Ed., 2002, 41, 3096-3129.

5 C. Dybowski and S. Bal, Anal. Chem., 2008, 80, 4295-4300.

6 K. J. D. Mackenzie and M. E. Smith, Multinuclear Solid-State NMR of Inorganic Materials, Pergamon, Oxford, 1st edn, 2002.

7 M. J. Duer, Solid-State NMR Spectroscopy Principles and Applications, Blackwell Science, Oxford, UK, 2002.

8 R. W. Schurko, Acc. Chem. Res., 2013, 46, 1985-1995.

9 A. P. M. Kentgens, Geoderma, 1997, 80, 271-306.

10 S. E. Ashbrook and M. J. Duer, Concepts Magn. Reson., 2006, 28A, 183-248.

11 S. E. Ashbrook, Phys. Chem. Chem. Phys., 2009, 11, 6892-6905.

12 J. V. Hanna and M. E. Smith, Solid State Nucl. Magn. Reson., 2010, 38, 1-18.

13 H. E. Rhodes, P.-K. Wang, H. T. Stokes, C. P. Slichter and J. H. Sinfelt, Phys. Rev. B: Condens. Matter Mater. Phys., 1982, 26, 3559-3568.

14 D. Massiot, I. Farnan, N. Gautier, D. Trumeau, A. Trokiner and J. P. Coutures, Solid State Nucl. Magn. Reson., 1995, 4, 241-248.

15 F. Fayon, I. Farnan, C. Bessada, J. Coutures, D. Massiot and J. P. Coutures, J. Am. Chem. Soc., 1997, 119, 6837-6843.

16 A. Medek, V. Frydman and L. Frydman, J. Phys. Chem. A, 1999, 103, 4830-4835.

17 A. S. Lipton, G. W. Buchko, J. A. Sears, M. A. Kennedy and P. D. Ellis, J. Am. Chem. Soc., 2001, 123, 992-993.

18 N. Pooransingh-Margolis, R. Renirie, Z. Hasan, R. Wever, A. J. Vega and T. Polenova, J. Am. Chem. Soc., 2006, 128, 5190-5208.

19 K. J. Ooms, V. V. Terskikh and R. E. Wasylishen, J. Am. Chem. Soc., 2007, 129, 6704-6705.

20 A. S. Lipton, R. W. Heck, W. A. de Jong, A. R. Gao, X. J. Wu, A. Roehrich, G. S. Harbison and P. D. Ellis, J. Am. Chem. Soc., 2009, 131, 13992-13999.

21 A. J. Rossini, R. W. Mills, G. A. Briscoe, E. L. Norton, S. J. Geier, I. Hung, S. Zheng, J. Autschbach and R. W. Schurko, J. Am. Chem. Soc., 2009, 131, 3317-3330.

22 P. J. Knijn, P. J. M. van Bentum, E. R. H. van Eck, C. Fang, D. L. A. G. Grimminck, R. A. de Groot, R. W. A. Havenith, M. Marsman, W. L. Meerts, G. A. de Wijs and A. P. M. Kentgens, Phys. Chem. Chem. Phys., 2010, 12, 11517-11535.

23 L. A. O'Dell, R. W. Schurko, K. J. Harris, J. Autschbach and C. I. Ratcliffe, J. Am. Chem. Soc., 2011, 133, 527-546.

24 B. J. Greer, V. K. Michaelis, M. J. Katz, D. B. Leznoff, G. Schreckenbach and S. Kroeker, Chem. - Eur. J., 2011, 17, 3609-3618. 
25 R. Hajjar, C. Volkringer, T. Loiseau, N. Guillou, J. Marrot, G. Ferey, I. Margiolaki, G. Fink, C. Morais and F. Taulelle, Chem. Mater., 2011, 23, 39-47.

26 F. A. Perras and D. L. Bryce, Angew. Chem., Int. Ed., 2012, 51, 4227-4230.

27 B. E. G. Lucier, K. E. Johnston, W. Q. Xu, J. C. Hanson, S. D. Senanayake, S. Y. Yao, M. W. Bourassa, M. Srebro, J. Autschbach and R. W. Schurko, J. Am. Chem. Soc., 2014, 136, 1333-1351.

28 C. A. O’Keefe, K. E. Johnston, K. Sutter, J. Autschbach, R. Gauvin, J. Trébosc, L. Delevoye, N. Popoff, M. Taoufik, K. Oudatchin and R. W. Schurko, Inorg. Chem., 2014, 53, 9581-9597.

29 R. Gupta, G. Hou, R. Renirie, R. Wever and T. Polenova, J. Am. Chem. Soc., 2015, 137, 5618-5628.

30 J. Catalano, A. Murphy, Y. Yao, G. P. A. Yap, N. Zumbulyadis, S. A. Centeno and C. Dybowski, Dalton Trans., 2015, 44, 2340-2347.

31 I. D. Seymour, D. S. Middlemiss, D. M. Halat, N. M. Trease, A. J. Pell and C. P. Grey, J. Am. Chem. Soc., 2016, 138, 9405-9408.

32 M. Soorholtz, L. C. Jones, D. Samuelis, C. Weidenthaler, R. J. White, M.-M. Titirici, D. A. Cullen, T. Zimmermann, M. Antonietti, J. Maier, R. Palkovits, B. F. Chmelka and F. Schüth, ACS Catal., 2016, 6, 2332-2340.

33 T. Kobayashi, F. A. Perras, T. W. Goh, W. Huang and M. Pruski, J. Phys. Chem. Lett., 2016, 7, 2322-2327.

34 F. H. Larsen, H. J. Jakobsen, P. D. Ellis and N. C. Nielsen, J. Phys. Chem. A, 1997, 101, 8597-8606.

35 F. H. Larsen, H. J. Jakobsen, P. D. Ellis and N. C. Nielsen, J. Magn. Reson., 1998, 131, 144-147.

36 I. Hung and Z. H. Gan, J. Magn. Reson., 2010, 204, 256-265.

37 R. Bhattacharyya and L. Frydman, J. Chem. Phys., 2007, 127, 194503.

38 L. A. O'Dell and R. W. Schurko, Chem. Phys. Lett., 2008, 464, 97-102.

39 K. J. Harris, A. Lupulescu, B. E. G. Lucier, L. Frydman and R. W. Schurko, J. Magn. Reson., 2012, 224, 38-47.

40 F. H. Larsen, H. J. Jakobsen, P. D. Ellis and N. C. Nielsen, Mol. Phys., 1998, 95, 1185-1195.

41 J. Trebosc, J. W. Wiench, S. Huh, V. S. Y. Lin and M. Pruski, J. Am. Chem. Soc., 2005, 127, 7587-7593.

42 G. Kervern, S. Steuernagel, F. Engelke, G. Pintacuda and L. Emsley, J. Am. Chem. Soc., 2007, 129, 14118-14119.

43 B. E. G. Lucier, A. R. Reidel and R. W. Schurko, Can. J. Chem., 2011, 89, 919-937.

44 B. E. G. Lucier, K. E. Johnston, D. C. Arnold, J. L. Lemyre, A. Beaupre, M. Blanchette, A. M. Ritcey and R. W. Schurko, J. Phys. Chem. C, 2014, 118, 1213-1228.

45 G. G. Briand, A. D. Smith, G. Schatte, A. J. Rossini and R. W. Schurko, Inorg. Chem., 2007, 46, 8625-8637.

46 R. K. Harris and A. Sebald, Magn. Reson. Chem., 1989, 27, 81-87.

47 S. P. Gabuda, S. G. Kozlova, V. V. Terskikh, C. Dybowski, G. Neue and D. L. Perry, Chem. Phys. Lett., 1999, 305, 353-358.

48 A. C. Larsson, A. V. Ivanov, K. J. Pike, W. Forsling and O. N. Antzutkin, J. Magn. Reson., 2005, 177, 56-66.
49 S. W. Sparks and P. D. Ellis, J. Am. Chem. Soc., 1986, 108, 3215-3218.

50 S. S. Wi, Z. H. Gan, R. Schurko and L. Frydman, J. Chem. Phys., 2015, 142, 064201.

51 A. C. Poppler, J. P. Demers, M. Malon, A. P. Singh, H. W. Roesky, Y. Nishiyama and A. Lange, ChemPhysChem, 2016, 17, 812-816.

52 A. J. Pell and G. Pintacuda, Prog. Nucl. Magn. Reson. Spectrosc., 2015, 84, 33-72.

53 G. Kervern, G. Pintacuda and L. Emsley, Chem. Phys. Lett., 2007, 435, 157-162.

54 A. J. Pell, R. J. Clement, C. P. Grey, L. Emsley and G. Pintacuda, J. Chem. Phys., 2013, 138, 114201.

55 N. P. Wickramasinghe and Y. Ishii, J. Magn. Reson., 2006, 181, 233-243.

56 S. K. K. Swamy, A. Karczmarska, M. Makowska-Janusik, A. Kassiba and J. Dittmer, ChemPhysChem, 2013, 14, 1864-1870.

57 Z. H. Gan, J. Am. Chem. Soc., 2006, 128, 6040-6041.

58 S. Cavadini, A. Lupulescu, S. Antonijevic and G. Bodenhausen, J. Am. Chem. Soc., 2006, 128, 7706-7707.

59 S. Cavadini, A. Abraham and G. Bodenhausen, Chem. Phys. Lett., 2007, 445, 1-5.

60 J. Trebosc, B. Hu, J. P. Amoureux and Z. Gan, J. Magn. Reson., 2007, 186, 220-227.

61 B. Hu, J. Trebosc and J. P. Amoureux, J. Magn. Reson., 2008, 192, 112-122.

62 O. Lafon, Q. Wang, B. W. Hu, F. Vasconcelos, J. Trebosc, S. Cristol, F. Deng and J. P. Amoureux, J. Phys. Chem. A, 2009, 113, 12864-12878.

63 S. Cavadini, V. Vitzthum, S. Ulzega, A. Abraham and G. Bodenhausen, J. Magn. Reson., 2010, 202, 57-63.

64 M. Shen, J. Trebosc, O. Lafon, F. Pourpoint, B. Hu, Q. Chen and J. P. Amoureux, J. Magn. Reson., 2014, 245, 38-49.

65 G. Tricot, J. Trebosc, F. Pourpoint, R. Gauvin and L. Delevoye, in Annual Reports on Nmr Spectroscopy, Vol 81, ed. G. A. Webb, 2014, vol. 81, pp. 145-184.

66 M. Deschamps and D. Massiot, in NMR of Quadrupolar Nuclei in Solid Materials, ed. R. E. Wasylishen, S. E. Ashbrook and S. Wimperis, John Wiley \& Sons, 2012.

67 Y. Ishii and R. Tycko, J. Magn. Reson., 2000, 142, 199-204.

68 Y. Ishii, J. P. Yesinowski and R. Tycko, J. Am. Chem. Soc., 2001, 123, 2921-2922.

69 J. W. Wiench, C. E. Bronnimann, V. S. Y. Lin and M. Pruski, J. Am. Chem. Soc., 2007, 129, 12076-12077.

70 D. H. Zhou, G. Shah, M. Cormos, C. Mullen, D. Sandoz and C. M. Rienstra, J. Am. Chem. Soc., 2007, 129, 11791-11801.

71 M. Shen, J. Trebosc, O. Lafon, Z. H. Gan, F. Pourpoint, B. W. Hu, Q. Chen and J. P. Amoureux, Solid State Nucl. Magn. Reson., 2015, 72, 104-117.

72 R. K. Harris, E. D. Becker, S. M. C. De Menezes, R. Goodfellow and P. Granger, Pure Appl. Chem., 2001, 73, 1795-1818.

73 A. Brinkmann and A. P. M. Kentgens, J. Am. Chem. Soc., 2006, 128, 14758-14759.

74 S. Jain, M. Bjerring and N. C. Nielsen, J. Phys. Chem. Lett., 2012, 3, 703-708. 
75 R. R. Ernst, G. Bodenhausen and A. Wokaun, Principles of Nuclear Magnetic Resonance in One and Two Dimensions, Oxford University Press, Oxford, 2nd edn, 1987.

76 S. K. Jain, A. B. Nielsen, M. Hiller, L. Handel, M. Ernst, H. Oschkinat, U. Akbey and N. C. Nielsen, Phys. Chem. Chem. Phys., 2014, 16, 2827-2830.

77 K. Basse, S. K. Jain, O. Bakharev and N. C. Nielsen, J. Magn. Reson., 2014, 244, 85-89.

78 V. Vitzthum, M. A. Caporini, S. Ulzega and G. Bodenhausen, J. Magn. Reson., 2011, 212, 234-239.

79 F. Taulelle, Solid State Sci., 2004, 6, 1053-1057.

80 R. L. Vold and G. L. Hoatson, J. Magn. Reson., 2009, 198, 57-72.

81 C. Martineau, B. Bouchevreau, Z. J. Tian, S. J. Lohmeier, P. Behrens and F. Taulelle, Chem. Mater., 2011, 23, 4799-4809.

82 X. Q. Kong, L. A. O’Dell, V. Terskikh, E. Ye, R. Y. Wang and G. Wu, J. Am. Chem. Soc., 2012, 134, 14609-14617.

83 F. A. Perras and D. L. Bryce, J. Phys. Chem. C, 2012, 116, 19472-19482.

84 S. E. Ashbrook and S. Sneddon, J. Am. Chem. Soc., 2014, 136, 15440-15456.

85 F. A. Perras, Pure Appl. Chem., 2016, 88, 95-111.

86 A. S. Tatton, T. N. Pham, F. G. Vogt, D. Iuga, A. J. Edwards and S. P. Brown, CrystEngComm, 2012, 14, 2654-2659.
87 L. A. O'Dell, R. L. He and J. Pandohee, CrystEngComm, 2013, 15, 8657-8667.

88 A. S. Tatton, T. N. Pham, F. G. Vogt, D. Iuga, A. J. Edwards and S. P. Brown, Mol. Pharmaceutics, 2013, 10, 999-1007.

89 S. Çınar, I. Tevis, A. J. Rossini, J. Chen, S. Thimmaiah, N. Bello, M. Foster, B. S. Chang and M. Thuo, 2016, manuscript in preparation.

90 Y. Nishiyama, X. Y. Lu, J. Trebosc, O. Lafon, Z. H. Gan, P. K. Madhu and J. P. Amoureux, J. Magn. Reson., 2012, 214, 151-158.

91 M. K. Pandey, H. Kato, Y. Ishii and Y. Nishiyama, Phys. Chem. Chem. Phys., 2016, 18, 6209-6216.

92 I. D. Tevis, L. B. Newcomb and M. Thuo, Langmuir, 2014, 30, 14308-14313.

93 Z. H. Gan, J. Magn. Reson., 2006, 183, 235-241.

94 F. H. Larsen, J. Skibsted, H. J. Jakobsen and N. C. Nielsen, J. Am. Chem. Soc., 2000, 122, 7080-7086.

95 R. Lefort, J. W. Wiench, M. Pruski and J. P. Amoureux, J. Chem. Phys., 2002, 116, 2493-2501.

96 M. Bak, J. T. Rasmussen and N. C. Nielsen, J. Magn. Reson., 2000, 147, 296-330.

97 Z. Tosner, T. Vosegaard, C. Kehlet, N. Khaneja, S. J. Glaser and N. C. Nielsen, J. Magn. Reson., 2009, 197, 120-134.

98 Z. Tosner, R. Andersen, B. Stevenss, M. Eden, N. C. Nielsen and T. Vosegaard, J. Magn. Reson., 2014, 246, 79-93. 